\title{
Passive heat mitigation possibility using meteorological data analysis of Phitsanulok Province, Thailand for building application in the tropics
}

\author{
Waraporn Rattanongphisat* \\ Energy Technologies Building Laboratory, Department of Physics, Faculty of Science, Naresuan University, \\ Phitsanulok 65000 Thailand \\ e-mail: warapornr@nu.ac.th
}

Received 11 Nov 2020

Accepted 15 Mar 2021

\begin{abstract}
Climate is characterized by the outdoor temperature and precipitation. The Equatorial climate, found in the tropics, presents a hot and humid climate that is commonly observed in Thailand. The maximum outdoor air temperature increases due to the increase of the global temperature. This will cause building energy demand to grow according to the increased utilization of air conditioners, the highest energy consuming appliance in buildings. This paper presents an investigation in the possibility of passive heat mitigation by analyzing meteorological data in Phitsanulok, Thailand, a city located in the tropics. Passive cooling techniques operate without a conventional energy supply and rely on weather parameters. The air temperature, relative humidity, wind speed and direction, and solar angles were employed for the analysis. Data recorded in $3 \mathrm{~h}$ intervals from 2014 to 2016 was retrieved from the meteorological department of Phitsanulok. The wind speed, outdoor temperature, and humidity were used to evaluate the ventilation potential. A sun path diagram was adopted to demonstrate the solar angles on buildings. The solar angle differs from one location to another and varies with the time of day and throughout the year. The simulated results can assist in the design of awning and/or roller blinds on fenestrations. The results indicate the period when natural ventilation can reduce the amount of mechanical cooling required, thus cutting down the energy consumption of buildings. The results showed around 20 to 30 percent annual energy savings could be achieved when natural ventilation is employed, while maintaining human comfort. Furthermore, shading devices can prevent sunlight from entering buildings and reduce the ensuing heat build-up, thus further reducing the energy needed.
\end{abstract}

KEYWORDS: passive heat mitigation, tropics, thermal comfort, meteorological data, energy saving

\section{INTRODUCTION}

Climate change has caused the rise of global temperatures, which directly affects building energy consumption. Prediction of energy consumption needed for office buildings at the end of the twenty first century has been studied, and the analysis shows that the annual cooling energy demand will increase in the summer and heating energy demand in the winter will decrease [1]. In warm climate areas, the summer would be even worse if cooling systems are used as the high outdoor temperatures would cause the interior to be very uncomfortable. This trend will also be seen in Thailand. By Köppen and Geiger climate classification, Thailand's climate is type A - Equatorial climate, and Phitsanulok as Aw - Equatorial savannah with a minimum temperature above $18^{\circ} \mathrm{C}$ and precipitation less than $60 \mathrm{~mm}$ in the winter [2]. The climate is also referred to as the tropics and has hot and humid characteristics. Thailand typically has three seasons, where the summer is from mid of February to mid of May, the rainy season is from mid of May to mid of October, and the winter is between mid of October to mid of February [3]. The warmest month is April with an average temperature of $33^{\circ} \mathrm{C}$ and the highest monthly temperature of $44.6{ }^{\circ} \mathrm{C}$ in 2016 . The coldest month is January where the lowest temperature recorded was $1.4^{\circ} \mathrm{C}$, but that did not last longer than a week. The annual relative humidity is around $72-74 \%$ and reduces to $62-69 \%$ in the summer. Because of the weather observed in Thailand, cooling systems are required to provide a thermal comfort environment. Recently, the energy consumption of buildings has greatly increased from the increased utilization of air conditioners. This accounted for 28 percent of the total energy consumption in Thailand last year in the residential building sector [4]. The use 
of mechanical air conditioning systems powered by electricity is common, and these systems consume large amounts of energy, which is more than 50\% of building energy consumption [5]. In contrast, passive cooling does not need power to accomplish thermal changes, and it relies on weather conditions and building designs. The important weather parameters are the outdoor air temperature, humidity, wind speed and direction, and the sun position while the design parameters are dependent on the building envelope, insulation, and direct sun protection. Several passive cooling techniques were reviewed including nocturnal radiation, natural ventilation as well as evaporative, geothermal, deep ocean and lake cooling [6]. Cooling by nocturnal ventilation had the best performance in arid regions while hot and humid regions had lower efficiency because of the low temperature difference. Earth and air are used to receive thermal energy as a heat sink for geothermal cooling and ventilation, respectively. Deep oceans, where there is cold sea water, a large heat sink, can be employed for cooling buildings near coastlines. High air velocity created by ventilation could increase the temperature that is considered comfortable. A practical application in Chennai, a hot and humid climate, showed that an air velocity of $1.6 \mathrm{~m} / \mathrm{s}$ allows an increase of $2.6^{\circ} \mathrm{C}$, while maintaining thermal comfort as interpreted from surveys [7]. Other studies have shown similar results in Thailand, where an air velocity of $0.2 \mathrm{~m} / \mathrm{s}$ at $28^{\circ} \mathrm{C}$ could provide acceptable comfort. Even above $34^{\circ} \mathrm{C}$, an air velocity above $3 \mathrm{~m} / \mathrm{s}$ would be in the comfort range; however, the noise of the fan would disturb mental work [8]. A higher air velocity is necessary to provide comfort at high air temperature and humidity [9]. The intensity of urban heat island effect is high in Bangkok, Thailand during the dry season and depends on wind direction [10]. The urban heat island is defined as a phenomenon that urban, densely populated areas or cities have a temperature that is higher than that of the surrounding areas. The city is occupied by tall buildings and dense roadways that reduce the amount of green area compared with the surrounding rural areas. Low rise buildings in the area would have limited available ventilation. Furthermore, building orientation affects the building energy consumption. Heat flux through different orientations of vertical windows has been studied [11]. It was reported that Southern oriented windows received the highest heat gain, followed by East, West, and North oriented windows for the case study in tropical climate regions. It was suggested that moveable exterior shading devices for windows could reduce the cooling load of the hospital building in tropical climates and save 9.8\% of the energy annually. The building envelope is the area that receives external heat, mostly from the sun, and causes increased indoor temperatures. A green façade is a heat relieving technique, which cools buildings by affixing some greenery to an external wall. It has been critically reviewed based on the fact that comparison is difficult due to the lack of standardized methods among several studies [12]. In other words, thermal performance of a green façade would be possibly compared only when specific criteria of the techniques including air patterns, weather, and design parameters are similar enough.

Thermal comfort influences the way energy is consumed in buildings particularly in tropical areas. Higher air temperatures and humidity cause a high demand for mechanical cooling systems. Occupants can reach the desired temperature easily when air conditioning is available. This sometimes causes the over use of energy. Many occupants would prefer to stay in slightly colder place as they can adjust their insulation level by wearing thick clothes or more layers of clothes. It is quite common that people wear a suit or jacket while sitting and doing light office work. In addition, there are many occasions that occupants put on a jacket to protect them from shivering when entering airconditioned public spaces such as exhibition halls, shopping malls, hotels, meeting rooms, conferences, and lecture rooms. Excess chilling costs both extra energy and money since this means wasting energy. An example is the case of indoor climate analysis for an air-conditioned classroom which found that a comfortable temperature was around $26^{\circ} \mathrm{C}$ and $27^{\circ} \mathrm{C}$ but the temperature was set lower [13]. The study suggested an energy saving of $18 \%$ by having a higher temperature setting and switching off the air conditioner half an hour before the class finished.

The objective of this paper is to investigate the possibility of passive heat mitigation in a tropic climate. Meteorological data of Phitsanulok, Thailand was employed to analyze a range of passive techniques for building applications. In this study, the passive techniques include climatic condition feasible for ventilation and solar heat gain reduction using shading devices. By using passive methods, the mechanical cooling period would decrease, along with the building energy consumption. 


\section{MATERIALS AND METHODS}

\section{Collection of data}

Phitsanulok is located at the coordinates: latitude $16^{\circ} 49^{\prime} \mathrm{N}$ and longitude $100^{\circ} 15^{\prime} \mathrm{E}$, which is in the lower Northern part of Thailand. The city is $49 \mathrm{~m}$ above the sea level. Two rivers flow through the city, and thus it has also been called the city of two rivers (Song Khwae in Thai). The climate of Phitsanulok is in general tropical, similar to other parts of the country. The warmest month is April with an average temperature of $31.7^{\circ} \mathrm{C}$ and the high temperature of $40^{\circ} \mathrm{C}$ is observed while the coldest month is January with the average temperature of $24.4^{\circ} \mathrm{C}$. The average relative humidity is $62 \%$ in the summer, $81 \%$ in the rainy season and $73 \%$ in the winter.

In this study, weather monitoring data including temperature, relative humidity, and wind speed and direction were retrieved from the meteorological department, Phitsanulok. The data sampling frequency was every three hours, thus the recorded data were displayed every three hours during the day throughout the year at 1:00, 4:00, 7:00, 10:00, 13:00, 16:00, 19:00, and 22:00, respectively. The data from 2014 to 2016 were used for the analysis of the influential parameters to access passive cooling techniques.

\section{Data Analysis}

A tabulation analysis of the weather data was employed. The data were rearranged by taking out the heading of each month's table and arranged in monthly and yearly tables, grouped by each type of data, and plotted as a pair or a group of parameters, e.g. temperature and relative humidity, wind velocity and direction, and temperature and wind velocity to identify the possibility of passive cooling approaches. According to the thirty years of recorded data in Phitsanulok, the mean velocity, temperature, and relative humidity of the previous three years is representative of the historical record of the local weather, thus three-year recorded data would be sufficient for the analytical study. The criteria for the weather parameters referred to previous standards and literature studies are presented next. The lower temperature limit was $12.8^{\circ} \mathrm{C}$ so as to avert a draft (unwanted local cooling of the body caused by air movement) [14]. The upper temperature limit for an adaptive comfort zone is $26^{\circ} \mathrm{C}$ [15]. The maximum indoor air velocity is $0.8 \mathrm{~m} / \mathrm{s}$ [14], and the maximum outdoor air velocity is $13.8 \mathrm{~m} / \mathrm{s}[16,17]$. The relative humidity is less than or equal to $60 \%$, but this could go up to 70 $80 \%$ for cases in the tropical climate of Thailand when the air velocity is greater than $1 \mathrm{~m} / \mathrm{s}$ [8]. Wind direction was recorded as an angle in degrees; hence, the angle is converted to direction, e.g. $90^{\circ}$ equal to East, $180^{\circ}$ equal to South, $270^{\circ}$ equal to West, and $360^{\circ}$ equal to North. In the analysis, the weather parameters were the outdoor temperature, relative humidity, wind speed, and wind direction, which fall into the range indicated earlier and are shown as a diagram (Fig. 1). The number of hours per year when outdoor weather conditions were suitable for natural ventilation was determined by multiplying the number of criterion data with the time interval.

\section{RESULTS AND DISCUSSION}

Fig. 2 shows the plot of the cumulative of the outdoor temperature. The amount of time that the outdoor temperature is lower than $26.5^{\circ} \mathrm{C}$ is shown to be around $3000 \mathrm{~h} /$ year. Wind speed varies mainly between $1 \mathrm{~m} / \mathrm{s}$ and $3 \mathrm{~m} / \mathrm{s}$ with speed rarely exceeding $3 \mathrm{~m} / \mathrm{s}$ (Fig. 3). Air can flow over the skin between 0.25 to $0.5 \mathrm{~m} / \mathrm{s}$ to provide human comfort without the feel of the wind flow. Once the air velocity is greater than $0.5 \mathrm{~m} / \mathrm{s}$ but not higher than $1 \mathrm{~m} / \mathrm{s}$, the occupants' comfort could be achieved while feeling the touch of the wind. Considering the outdoor temperature and wind speed, a large number of data points are at temperatures lower than the upper limit of $26^{\circ} \mathrm{C}$ and wind speed higher than $2 \mathrm{~m} / \mathrm{s}$ but lower than the upper limit of $13.8 \mathrm{~m} / \mathrm{s}$ that can be employed for building ventilation. This points out the potential use of passive cooling such as natural ventilation. Natural ventilation hour is the period when the weather condition is appropriate for natural airflow to cool the space down. The outdoor temperature is the significant parameter in this method. Although the humidity could cause discomfort, in this study it is considered that people are familiar with the high humidity, thus a relative humidity less than $80 \%$ can be accepted. In summer, the relative humidity is low, and it could reach adaptive thermal comfort using natural ventilation.

The plots of temperature versus relative humidity and temperature versus wind speed show that wind is available at various outdoor temperatures, mostly around $15^{\circ} \mathrm{C}$ and $32^{\circ} \mathrm{C}$ (Fig. 3). The majority of wind speed is between 1 and $3 \mathrm{~m} / \mathrm{s}$ which is sufficient to provide natural ventilation. It was reported that an outdoor temperature above $23^{\circ} \mathrm{C}$ could not maintain the interior temperature to the 


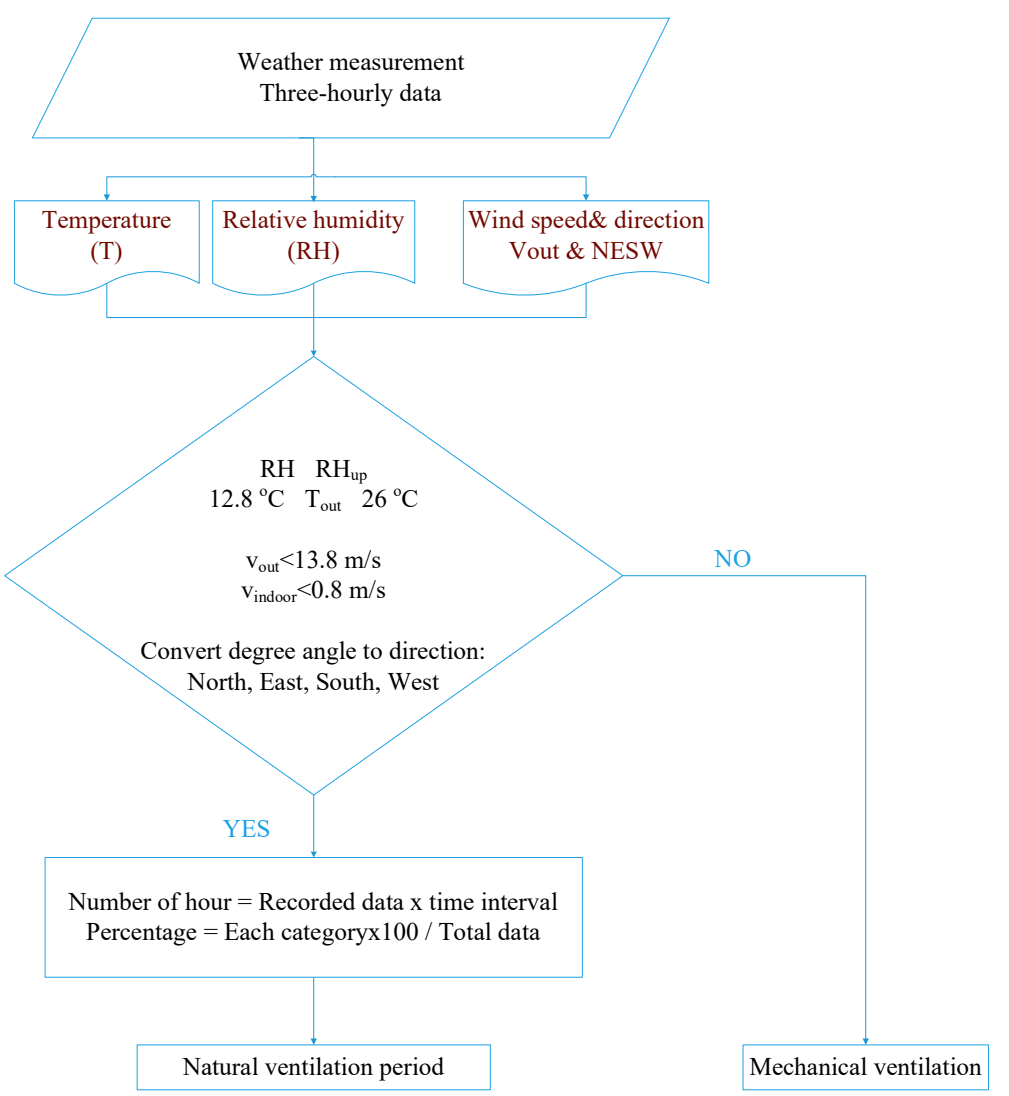

Fig. 1 Analysis of natural ventilation period from the weather data.

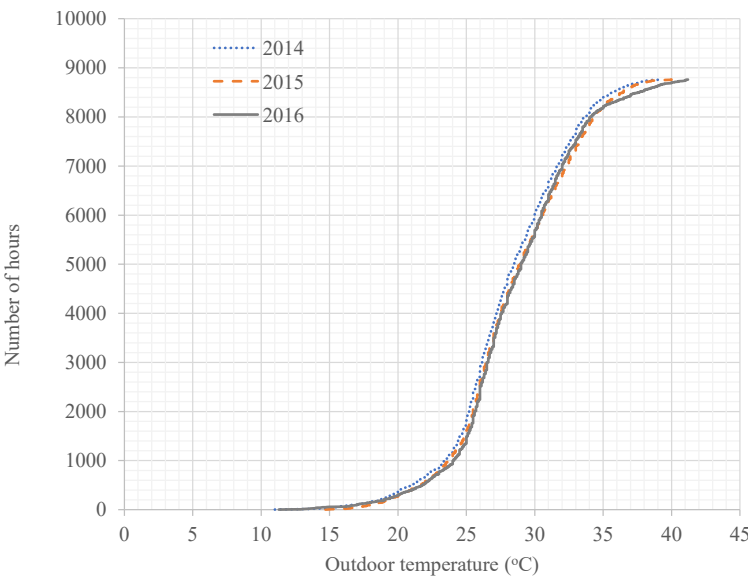

Fig. 2 Cumulative distribution of outdoor temperature.

acceptable comfort standard, according to the study in hot and humid climates; however, the influence of air velocity has not been mentioned [15]. According to the literature study in Thailand, the comfortable temperature can go up to $28^{\circ} \mathrm{C}$ even with a low air speed of $0.2 \mathrm{~m} / \mathrm{s}$ [8]. Hence, the period of

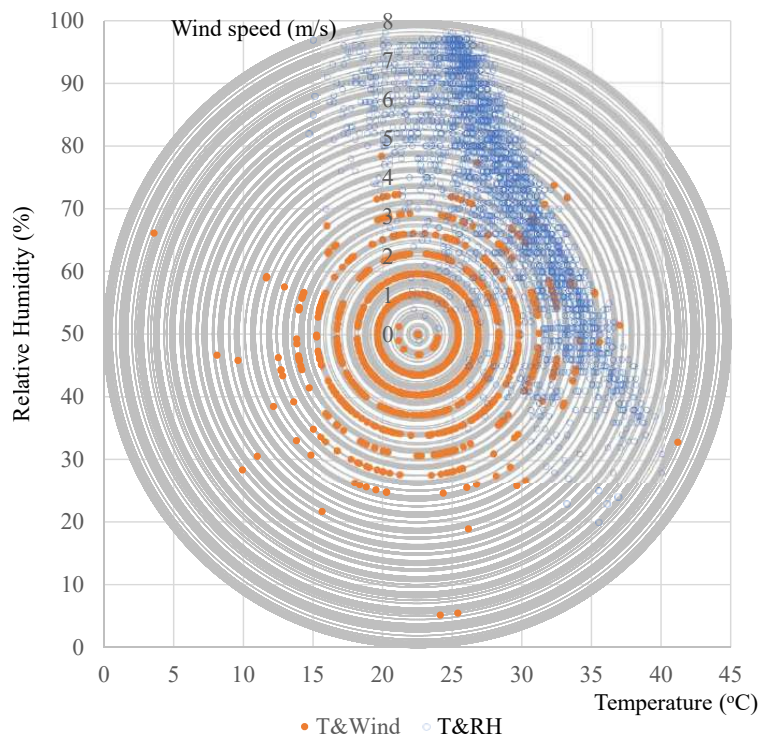

Fig. 3 Profile of the annual outdoor temperature, relative humidity, and wind speed in Phitsanulok.

potential natural ventilation could be greater than the limit indicated in the ASHRAE standard $[14,18]$. 


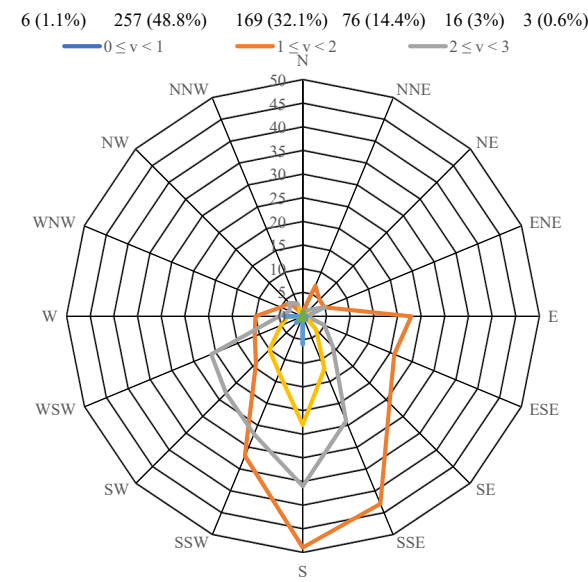

2014

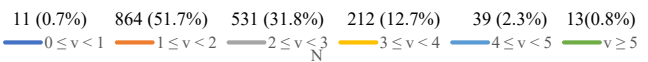

$8(1.8 \%) \quad 178(39 \%) \quad 160(35.1 \%) \quad 70(15.4 \%) \quad 27(5.9 \%) \quad 13(2.9 \%)$

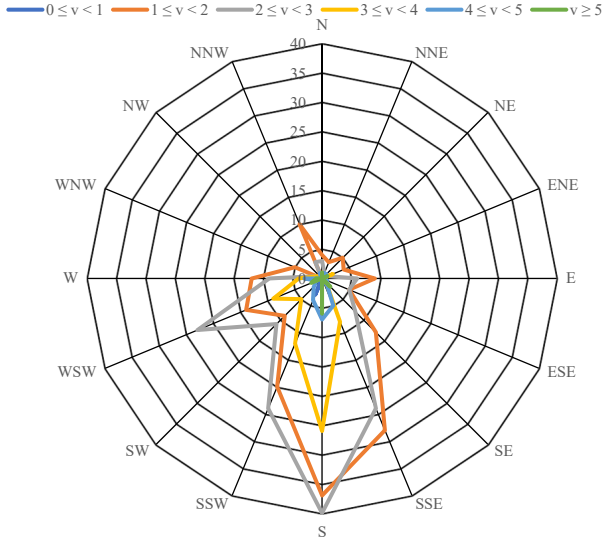

2015

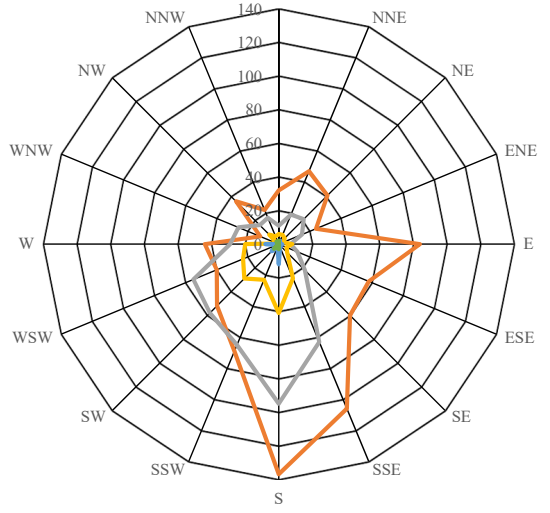

$9(0.6 \%) \quad 645(41.3 \%) \quad 549(35.2 \%) \quad 245(15.7 \%) \quad 82(5.3 \%) \quad 31(2 \%)$

$-0 \leq \mathrm{v}<1-1 \leq \mathrm{v}<2-2 \leq \mathrm{v}<3-3 \leq \mathrm{v}<4-4 \leq \mathrm{v}<5-\mathrm{v} \geq 5$

$\begin{array}{llllll}6(1.1 \%) & 176(32.9 \%) & 205(38.3 \%) & 87(16.3 \%) & 45(8.4 \%) & 16(3 \%)\end{array}$
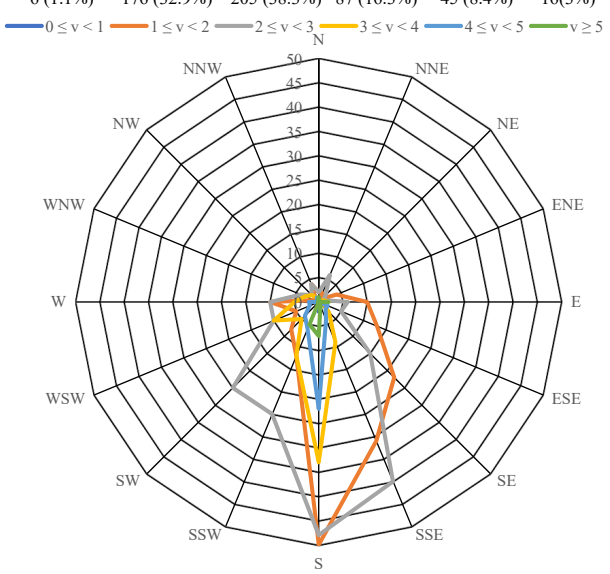

2016

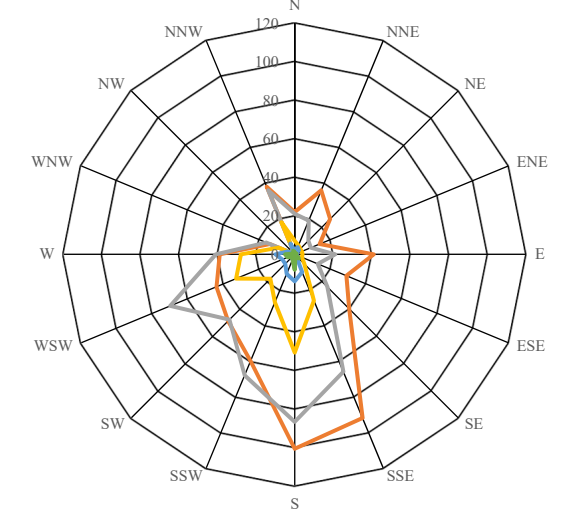

$41(2.1 \%) \quad 848(43.67 \%) \quad 698(35.9 \%) \quad 233(12 \%) \quad 91(4.7 \%) \quad 34(1.7 \%)$

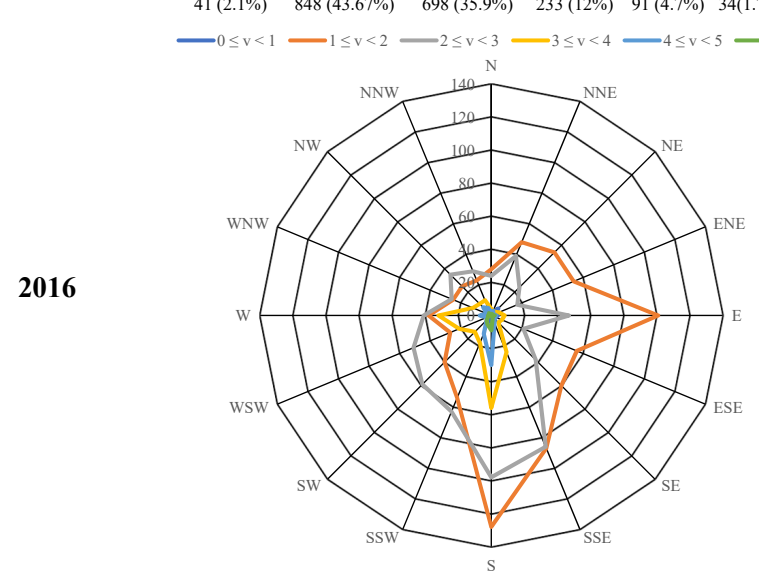

Fig. 4 Yearly wind rose diagram ranging from 0 to greater than $5 \mathrm{~m} / \mathrm{s}$ including number of incidents and percentage of time from 2014 to 2016 in Phitsanulok during the summer.

Another experimental study also provided similar results that an air temperature of $28^{\circ} \mathrm{C}$ is more preferable than $26^{\circ} \mathrm{C}$ at airspeed of $0.2 \mathrm{~m} / \mathrm{s}$ when the subjects in the warmer conditions are allowed to choose the airspeed according to their will [19].
This could provide a large amount of energy savings when the outdoor air is at the upper temperature that can be utilized for natural ventilation with the same result as the controlled air velocity in an airconditioned space [15]. 


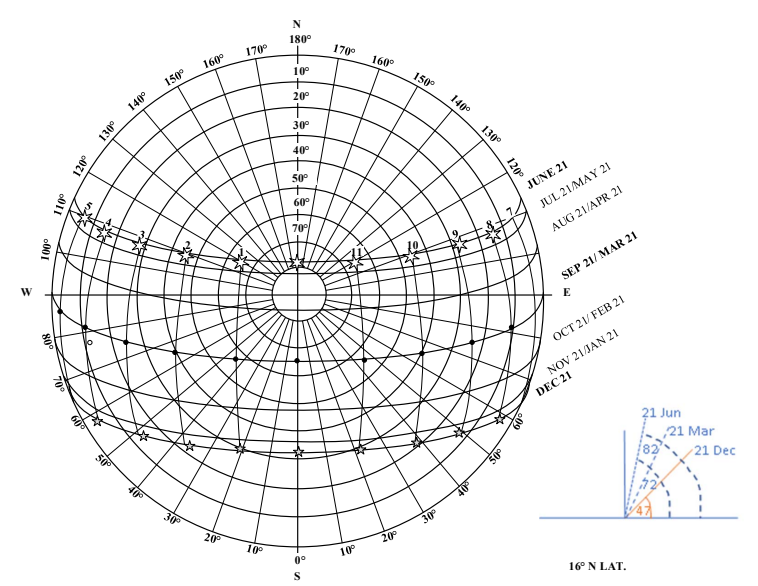

Fig. 5 Sun path diagram for the latitude of $16^{\circ} \mathrm{N}$ and indicated points on the diagram when the solar altitude and azimuth angles change with the time of day.

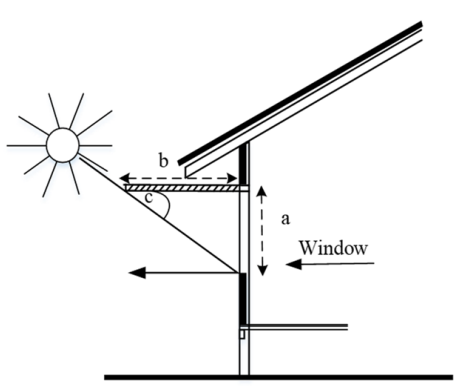

Fig. 6 Shading device.

Fig. 4 shows the direction of wind in an annual and a summer profile. The yearly wind flow is mostly from the South followed by from the East. The wind speed is mainly between 1 and $2 \mathrm{~m} / \mathrm{s}$, and 2 and $3 \mathrm{~m} / \mathrm{s}$ for the Southern and Eastern directions, respectively. The air velocity is high and sufficient for natural ventilation. It also suggests building openings should be positioned in these two directions and its opposite direction, opening in the South and North for example, to allow efficient crossflow ventilation. In the case of the summer season that requires cooling, the natural cooling can be used to provide comfort in the morning between mid-February and mid-May when the wind flows mostly from the South, thus it is best recommended that building openings shall be on both the North and the South for crossflow ventilation.

The solar angle can be calculated to provide the sun position with the solar altitude angle, the angle between the horizon and the line to the sun, and solar azimuth angle, the angular displacement from the south of the projection of the radiation beam on the horizontal plane [20]. In addition to the calculation for the solar angle, they could be plotted on the sun path diagram at latitude $16^{\circ} \mathrm{N}$ for Phitsanulok (Fig. 5). The azimuth and altitude angle of the sun on a building at Phitsanulok could be drawn on the sun path diagram for four significant days of the year: 21 March (Spring Equinox); 21 June (Summer Solstice); 21 September (Fall Equinox); and 21 December (Winter Solstice). The two angles vary according to the time of day.

Sun control can prevent direct sunlight entering buildings, mitigate heat, and reduce cooling energy requirements (Fig. 6). The length of the awning can be calculated according to the solar angles: $b=a / \tan c$, when $a$ is the window height and $c$ is the solar altitude. With a window height of $1.2 \mathrm{~m}$, the awning would be between 0.39 and $1.1 \mathrm{~m}$ long relating to the altitude angle at noon. The awning length $(b)$ when paying attention to the summer will be between $1.3 \mathrm{~m}$ and $1 \mathrm{~m}$ relating to the lower solar angle at 3:00 pm between 15 February and 15 May. The afternoon sun strongly affects the building comfort where the awning could provide good solar protection, thus the angle at 3:00 pm should be paid attention to. The design of the awning length at $1.3 \mathrm{~m}$ shall be chosen as to provide whole year solar protection when the window is located on the side that receives afternoon sun. External roller blind is recommended to provide a more efficient way to mitigate heat from the sun since the internal blind could release heat into the building's interior.

\section{CONCLUSION}

The meteorological data of Phitsanulok Province, Thailand was analyzed to demonstrate the possibility of natural cooling to mitigate the heating of buildings in the tropical climate. The research finds that the natural ventilation could be employed during the summer season. The three weather parameters found to be associated with natural ventilation are outdoor temperature, relative humidity, and wind speed at parameters lower than $26^{\circ} \mathrm{C}, 70 \%$, and $3 \mathrm{~m} / \mathrm{s}$, respectively. The natural ventilation hours were up to $3000 \mathrm{~h} /$ year and can be reached when adaptive thermal comfort is considered in the tropics. Energy saving due to the reduction in the period when mechanical cooling systems are required could be achieved. The prevailing wind direction in the summer is in the South, suggesting the position of building opening for efficient crossflow ventilation from the South to North. Several passive techniques might be necessary and should be considered and further examined. 
Acknowledgements: This work was supported by Faculty of Science, Naresuan University. The author would like to thank Assist. Prof. Dr. Kyle V. Lopin for manuscript editing.

\section{REFERENCES}

1. Wan K, Li D, Pan W, Lam J (2012) Impact of climate change on building energy use in different climate zones and mitigation and adaptation implications. Appl Energy 97, 274-282.

2. Kottek M, Grieser J, Beck C, Rudolf B, Rubel F (2006) World map of Köppen-Geiger climate classification updated. Meteorologische Zeitschrift 15, 259-263.

3. Thai Meteorological Department (2019) Annual Weather Summary, TMD, Bangkok, Thailand.

4. Energy Policy and Planning Office (2020) Electricity Energy Statistic, EPPO, Ministry of Energy, Thailand.

5. Department of Alternative Energy Development and Efficiency (2021) Energy Conservation for Air Conditioning System, DEDE, Ministry of Energy, Thailand, Available at: http://webkc.dede.go.th/ testmax/node/3850.

6. Samuel DGL, Nagendra SMS, Maiya MP (2013) Passive alternatives to mechanical air conditioning of building: A review. Build Environ 66, 54-64.

7. Deb C, Ramachandraiah A (2010) Evaluation of thermal comfort in a rail terminal location in India. Build Environ 45, 2571-2580.

8. Khedari J, Yamtraipat N, Pratintong N, Hirunlabh J (2000) Thailand ventilation comfort chart. Energy Build 32, 245-249.

9. Candido C, Dear RJ, Lamberts R, Bittencourt L (2010) Air movement acceptability limits and thermal comfort in Brazil's hot humid climate zone. Build Environ 45, 222-229.

10. Kamma J, Manomaiphiboon K, Aman N, Thongkamdee T, Chuangchote S, Bonnet S (2020) Urban heat island analysis for Bangkok: multi-scale temporal variation, associated factors, directional dependence, and cool island condition. ScienceAsia 46, 213-223.

11. Dutta A, Samanta A, Neogi S (2017) Influence of orientation and the impact of external window shading on building thermal performance in tropical climate. Energy Build 139, 680-689.

12. Hunter AM, Williams NSG, Rayner JP, Aye L, Hes D, Livesley SJ (2014) Quantifying the thermal performance of green facades: a critical review. Ecol Eng 63, 102-113.

13. Rattanongphisat W, Prachaona T, Harfield A, Sato K, Hanaoka O (2017) Indoor climate data analysis based a monitoring platform for thermal comfort evaluation and energy conservation. Energy Procedia 138, 211-216.

14. ASHRAE (2020) Standard 55 - Thermal Environmental Conditions for Human Occupancy, ASHRAE Inc., Georgia, USA.

15. de Dear RJ, Brager GS (2002) Thermal comfort in naturally ventilated buildings: revisions to ASHRAE Standard 55. Energy Build 34, 549-561.

16. Tong Z, Chen Y, Malkawi A (2017) Estimating natural ventilation potential for high-rise buildings considering boundary layer meteorology. Appl Energy 193, 276-286.

17. Ploemen J, Nijs L, Pleysier J, Schipper H (2011) Wind-induced sound on buildings and structures. In: Proc 13th International Conference on Wind Engineering (ICWE 13), Amsterdam.

18. ASHRAE (2009) ASHRAE Handbook - Fundamentals, ASHRAE Inc., Georgia, USA.

19. Toftum J, Melikov AK, Rasmussen LW, Kuciel AA, Cinalska EA, Tynel A, Bruzda M, Fanger PO (2000) Human Response to Air Movement. Part I. Preference and Draft Discomfort, DTU International Center for Indoor Environment and Energy, Lyngby.

20. Duffie JA, Beckman WA (1991) Solar Engineering of Thermal Processes, Wiley, New York. 